\title{
A GIANT ADRENAL PSEUDOCYST PRESENTING WITH RIGHT HYPOCHONDRALGIAAND CACHEXIA: A CASE REPORT
}

\author{
ABDUS SALAM, ${ }^{1}$ MUSLINA AKHTER, ${ }^{2}$ ZAHID HASAN, ${ }^{3}$ MAHFUZUL KABIR ${ }^{4}$ \\ ${ }^{1}$ Department of Urology, Cox's Bazar Medical College, Cox's Bazar, ${ }^{2}$ Department of Obs \& Gynecology, International \\ Islamic Medical College, Chittagong, ${ }^{3}$ Department of Urology, United Hospital, Dhaka, ${ }^{4}$ Department of Pediatric Surgery, \\ Cox's Bazar Medical College, Cox's Bazar.
}

\begin{abstract}
Adrenal cysts are rare clinical condition that can present as abdominal swelling and chronic abdominal pain with weight loss. A 26 year old girl presented to our hospital with a 3 years history of right sided abdominal swelling and cachexia. Ultrasound of the abdomen reaveled a cystic area measuring $20 \times 18 \mathrm{~cm}$ below the liver. Computed tomography scan showed a large cystic homogenous mass measuring $20 \times 18 \times 18.5 \mathrm{~cm}$ in the right hypochondrium with most likely origin from the right adrenal gland. IVU showed left sided kidney was absent and left sided crossed ectopia was present. Both kidney on right side was pushed downwards. limited work up for hormone done. Hypersecretion was negative.A laparotomy with right adrenalectomy was performed. Final pathology showed a benign adrenal endothelial cyst.post operative period was unevenful. Surgical resection appears a safe and reasonable management strategy in a patient with adrenal cyst.
\end{abstract}

Bangladesh J. Urol. 2015; 18(1): 43-46

\section{Introduction}

A gigantic adrenal tumor is a rare finding. In 1903, Doran attributed the first case of adrenal cyst to Greiselius[1]. There were only seven cases of adrenal cyst reported by 1907 . Wahl questioned the rarity of adrenal cysts in 1951 and found an autopsy incidence of 1 in 1555[2]. The paucity of reports in the literature was a manifestation of clinical silence rather than true rarity. In1966, Foster described 220 cases of adrenal cyst in the world,s literature[3], while in 1979 Incze etal. Reported 250 cases[4]. In the lack of surgery, the differential diagnosis is difficult. Thus ,the surgery becomes an important tool to evaluate the case. The adrenal cysts are exceptional. Because of the haemorrhage, the diameters of the cyst may enlarge rapidly but the clinical picture varies from asymptomatic (incidentaloma discovered by a random ultrasound or CT) to acute complications such as abdominal pain, hypovolemic shock.

\section{Case Presentation}

In August 2014 ,a 26 year old female patient was admitted in private hospital in Chittagong with an intra

Correspondences: Abdus Salam, Department of Urology, Cox's Bazar Medical College, Cox's Bazar. E-mail: salamuro@ yahoo.com abdominal cystic mass on right hypochondrium for 3 years. Moderate abdominal pain with associated weight loss for last 2 years. A previous Transabdominal ultrasonography revealed an oval fluid filled space approximately $180 \mathrm{~mm}$ in diameter, situated in the upper pole of the right kidney. Left kidney was absent. Intravenous urography showed right sided crossed ectopia with a cystic mass which pushing down the position of the right kidney. CT scan showed a large cyst, homogenous mass in right hypochondrium. Origin of the mass was undetermined. The mass measured $20 \times 18 \times 18.5 \mathrm{~cm}$ in craniocaudal, anteroposteror and trasverse diameter. On clinical examination, a clearly defined mass occupied in the right hypochondrium and that was not tender.Her blood pressure was $120 / 80$ $\mathrm{mmHg}$. Laboratory investigation showed all normal parameter except moderate anemia. ( $\mathrm{Hb} \%$ was $9 \mathrm{gm} /$ dl). The hormonal examination, serum catecholamines, cortisol, aldosterone were all within normal limit. Fasting blood sugar, renal function liver function and chest $x$ ray were normal .Based on these findings, patient was diagnosed as having an right adrenal cyst. There fore the patient was qualified for operation. Right 12 rib bed incision was made Acystic lesion from right upper pole 
was removed. On operative findings there was two kidney on right side.post operative period was uneventful and the patient was discharged in good general condition.

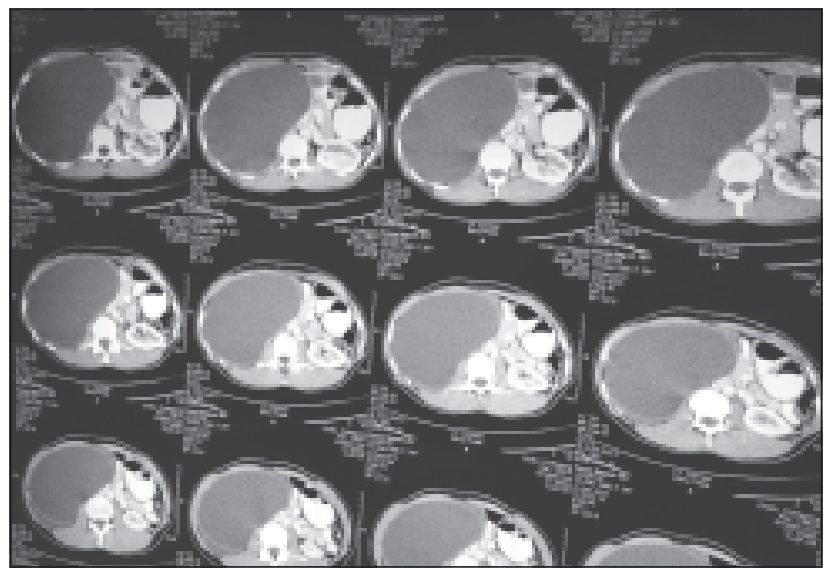

Fig.-1: An enhanced computed tomography of abdomen revealed a giant homogenous low density mass lesion in the right adrenal region.

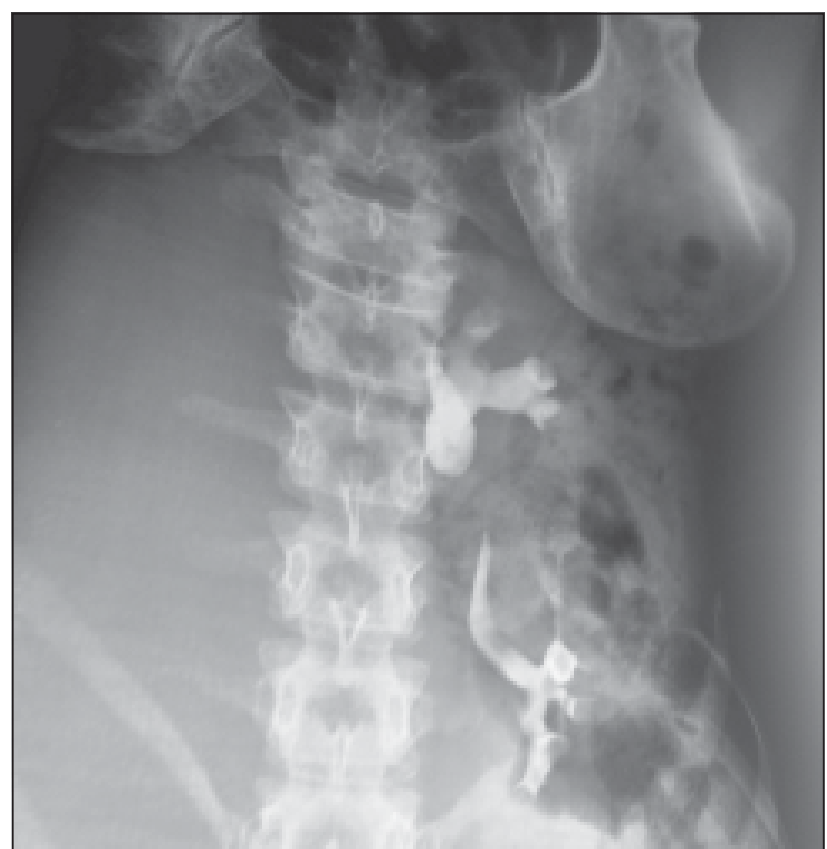

IVU findings of the patient

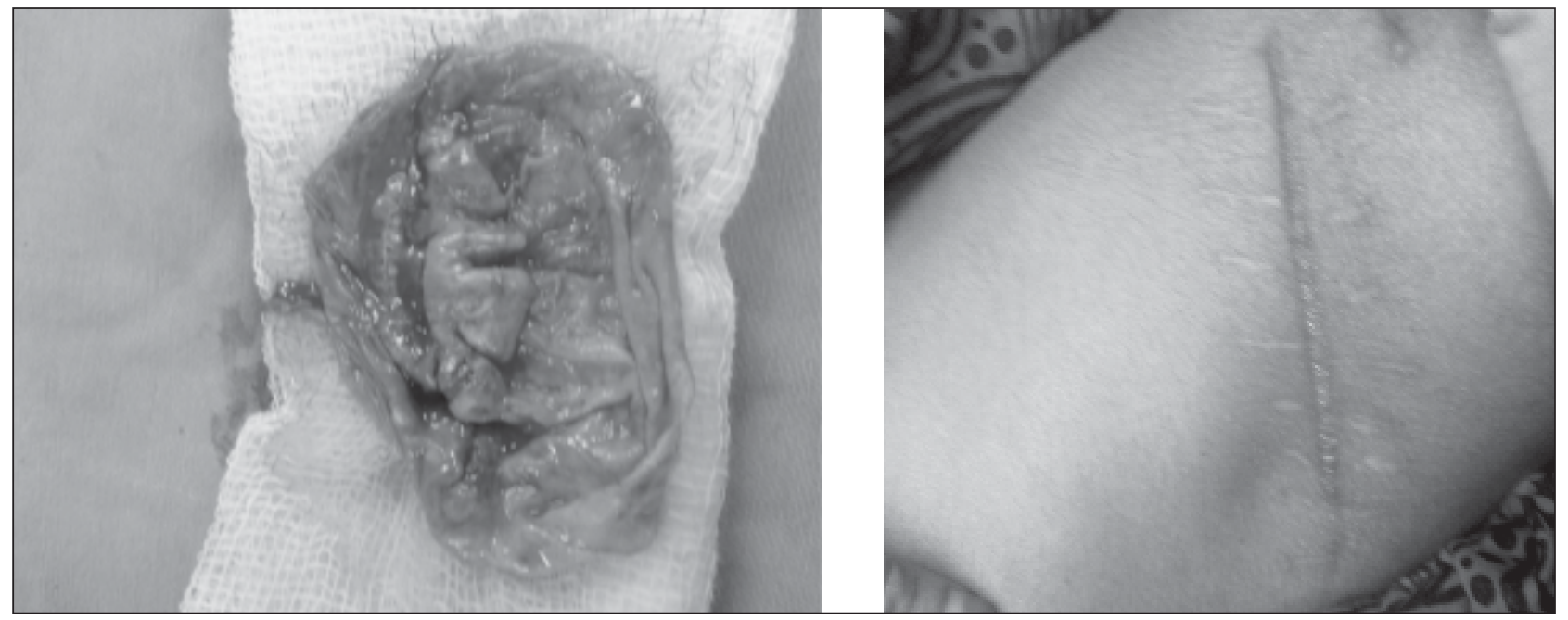

Cyst after removal \& the scar mark

The pathological examination pointed a cystic structure devoid of linning epithelium, composed of fibrocollagenous tissue with old haemorrhage and infiltration of chronic inflammatory cells. Cyst wall contains compressed adrenal tissue.

\section{Discussion:}

Adrenal cysts are rare and the documented incidence varies between $0.064 \%$ and $0.18 \%$ in autopsy series [5]. However, the rate of detection of adrenal cysts has risen dramatically due to the more frequent use of CT and MRI imaging studies in recent years, which account for approximately $5 \%$ of incidentally discovered adrenal lesions [6]. Adrenal cysts may occur at any age but most are found in the 3rd to 5th decades [3]. In some series, a female preponderance of about 3:1 has been noted for unknown reasons [7].

Histologically, cystic formations of the adrenals are divided into four groups: parasitic; epithelial (true cysts); endothelial (vascular cysts with an endothelial lining); and pseudocysts [8]. There are also other more infrequent subtypes such as lymphangiomas, mesothelial cysts, dermoid cysts or cystic adrenal 
carcinomas. Adrenal pseudocysts represent approximately $80 \%$ of cystic adrenal masses $[9,10]$. Adrenal pseudocysts are devoid of an epithelial or endothelial lining, arise within the adrenal gland and are surrounded by a fibrous tissue wall.

The true origin of adrenal pseudocyst remains a mystery. One theory suggests that these lesions result from an intra-adrenal hemorrhage caused by trauma, a sepsis event or some other form of shock[11]. The initial injury leads to the development of a cavity with a scarred, fibrous lining that slowly enlarges over time. Another theory suggests that these lesions are true cysts that have lost their cellular lining because of the inflammation and bleeding within the cyst. The etiology of our patient's pseudocyst seemed to be similar to latter theory. The patient's lesion was diagnosed as a true cyst at first because of its homogeneity on the US finding. The internal structure of the cyst changed into heterogeneous and, finally, the cyst was diagnosed as pseudocyst.

Most adrenal cysts are asymptomatic because of their small size[3]. In the case of large cysts, symptoms occur in relation to their compression of adjacent organs. This seems to be a common feature in most pseudocysts (either they arise from the adrenals or from the pancreas) and seems to be related to the chronically increased intra-abdominal pressure that these cyst introduce [12]. The three most prominent clinical features are: a dull pain in the adrenal area; gastrointestinal symptoms; and a palpable mass. They seldom cause adrenal hypofunction, Cushing's syndrome or pheochromocytoma[8]. Acute abdomen or a tender mass may occasionally be found, when intracystic hemorrhage, rupture or infection occurs [8]. Our patient had a right hypochondralgia with tenderness and high fever due to infection, with no gastrointestinal complaints. He had no hypertension during the follow-up period.

Due to the wide use of the diagnostic imaging modalities, the detection rate of adrenal cystic lesions is increasing. However, a preoperative confirmatory diagnosis of a large adrenal cyst can be very difficult because of the indistinct boundary with surrounding organs and adhesion to neighboring organs. Furthermore, even with integrated fluorine-18 fluorodeoxyglucose positron emission tomography (PET), adrenal lesions may be identified as false-positive at PET, including adrenal adenomas, adrenal endothelial cysts and inflammatory and infectious lesions[13].

The differential diagnosis of adrenal pseudocysts includes splenic, hepatic and renal cysts, as well as mesenteric or retroperitoneal cysts, urachal cysts and solid adrenal tumors. An exact diagnosis is clinically important in large lesion because adrenal incidentalomas larger than $5 \mathrm{~cm}[14]$ carry an increased risk of adrenal malignancy. The reported incidence of malignancy in adrenal cystic lesions is approximately $7 \%[14]$.

On CT, most pseudocysts demonstrate well-demarcated round or oval masses with fluid density but the CT features of pseudocysts are more complicated than simple cysts due to the complicated components such as septa, blood and soft-tissue components. The cysts wall shows occasional calcification. MRI is the best modality for visualizing the complicated intracystic components. Moreover, MRI is particularly sensitive for detecting intracystic hemorrhage, which shows hyperintense on both T1- and T2-weighted images.

Treatment of adrenal cysts is determined by size and the symptoms related to the mass. Surgical excision is indicated by the presence of symptoms, a suspicion of malignancy and an increase in size, or the detection of, a functioning adrenal cyst. Surgical treatment may not be necessary for small asymptomatic lesions as most cysts are benign [14]. If the adrenal lesion is diagnosed as a simple nonfunctioning cyst, the patient may be treated conservatively with aspiration alone. In large abscesses, where the probability of rupture is increased, transcutaneous drainage should be avoided as it may increase the risk of microbial load dissemination [15].

\section{Conclusion}

An adrenal pseudocyst is an uncommon clinical finding and is even rarer when it is giant-sized and infected. Surgery is required for symptomatic cases in order to relieve the symptoms and in cases of uncertain diagnosis. Radiological and clinical features of the tumor are nonspecific, thus, histopathological examination is essential in order to establish a definitive diagnosis.

\section{Conflict of Interest : None Declared}

\section{References}

1. Doran AHG. Cystic tumor of the supra-renal body successfully removed by operation. BMJ 1908, 1558-1563.

2. Wahl HR. Adrenal cysts. Am J Pathol 1951, 27:758.

3. Foster D. Adrenal cysts: Review of literature and report of case. Arch Surg 1966, 92:131-143. PubMed Abstract| Publisher Full Text.

4. Incze JS, Lui PS, Merrian JC, Austin G, Widrich WC, Gerzof SG. Morphology and pathogenesis of 
A Giant Adrenal Pseudocyst Presenting with Right Hypochondralgia and Cachexia

adrenal cysts. Am J Pathol 1979, 95:423-432. PubMed Abstract | PubMed Central Full Text

5. Rozenblit A, Morehouse HT, Amis ES Jr: Cystic adrenal lesions: CT features. Radiology 1996, 201(Suppl 2):541-548. PubMed Abstract | Publisher Full Text

6. Masumori N, Adachi $\mathrm{H}$, Noda $\mathrm{Y}$, Tsukamoto $\mathrm{T}$ : Detection of adrenal and retroperitoneal masses in a general health examination system. Urology 1998, 52(Suppl 4):572-576. PubMed Abstract | Publisher Full Text

7. Abeshouse GA, Goldstein RB, Abeshouse BS: Adrenal cysts: Review of the literature and report of three cases. J Urol 1959, 81(Suppl 6):711-719. PubMed Abstract

8. Gaffey MJ, Mills SE, Fechner RE, Bertholf MF, Allen MS Jr: Vascular adrenal cysts: a clinicopathologic and immunohistochemical study of endothelial and hemorrhagic (pseudocystic) variants. Am J Surg Pathol 1989, 13(Suppl 9):740747. PubMed Abstract | Publisher Full Text

9. Erickson LA, Lloyd RV, Hartman R, Thompson G: Cystic adrenal neoplasms. Cancer 2004, 101:15371544. PubMed Abstract | Publisher Full Text

10. Bellantone R, Ferrante A, Raffaelli M, Boscherini M, Lombardi CP, Crucitti F: Adrenal cystic lesions: report of 12 surgically treated cases and review of the literature. J Endocrinol Invest 1998, 21:109114. PubMed Abstract
11. Foroughi E: Calcified simple parenchymal cyst of the adrenal gland. $J$ Urol 1965, 94(Suppl 5):504510. PubMed Abstract

12. Papavramidis TS, Duros V, Michalopoulos A, Papadopoulos VN, Paramythiotis D, Harlaftis N: Intra-abdominal pressure alterations after large pseudocyst transcutaneous drainage. BMC Gastroenterol 2009, 9:42-46. PubMed Abstract | BioMed Central Full Text | PubMed Central Full Text

13. Chong Semin, Lee Kyung, Kim Ha, Kim Yoon, Kim Byung-Tae, Chung Myung, Chin YiA, Kwon Ghee: Integrated PET-CT for the characterization of adrenal gland lesions in cancer patients: diagnostic efficacy and interpretation pitfalls. Radiographics 2006, 26(Suppl 6):1811-24. discussion 1824-1826 PubMed Abstract | Publisher Full Text

14. Kasperlik-Zaªska AA, Otto M, Cichocki A, Ros $^{3}$ onowska E, S ${ }^{3}$ owinska-Srzednicka J, Zgliczyñski W, Jeske W, Papierska L, To ${ }^{33}$ oczko T, Polañski J, S3apa R: 1,161 patients with adrenal incidentalomas: indications for surgery. Langenbecks Arch Surg 2008, 393(Suppl 2):121126. PubMed Abstract | Publisher Full Text

15. Papavramidis TS, Sapalidis K, Pappas D, Karagianopoulou G, Trikoupi A, Souleimanis CH, Papavramidis ST: Gigantic hepatic amebic abscess presenting as acute abdomen: a case report. $J$ Med Case Reports 2008, 2:325. PubMed Abstract | BioMed Central Full Text | PubMed Central Full Text.

\section{Abbreviations}

CT: Computed Tomography; US: Ultrasound. 